\title{
Efeitos de Dietas com Diferentes Níveis de Fibra em Detergente Neutro e do Tamanho de Poros de Sacos de Náilon Incubados no Rúmen sobre a Fauna Ruminal em Bubalinos e Bovinos ${ }^{1}$
}

\author{
Maria Helena Tieghi Franzolin², Antonio Carlos Silveira ${ }^{3}$, Raul Franzolin 4
}

\begin{abstract}
RESUMO - Quatro bubalinos e quatro bovinos, fistulados no rúmen, foram distribuídos aleatoriamente a dois quadrados latinos (4 x 4) para avaliar os efeitos de rações com quatro níveis de FDN (54, 60, 66 e 72\%) e de dois tamanhos de poros em sacos de náilon (53 e $100 \mathrm{~mm}$ ) sobre a população de protozoários ciliados no conteúdo ruminal e dentro dos sacos incubados em diversos tempos. Não houve diferença nos diversos gêneros estudados e no total de protozoários nas amostras dos sacos de náilon entre 53 e 100 mm. As concentrações de Entodinium e de total de protozoários do conteúdo ruminal elevaram-se até o nível de $66 \%$ de FDN, com queda acentuada em $72 \%$ nos bubalinos, enquanto nos bovinos houve redução com o aumento de FDN na ração. Houve diferenças nas concentrações dos protozoários da subfamília Diplodiniinae, Epidinium e Dasytricha entre bubalinos e bovinos, dentro das amostras incubadas em sacos com poros de $53 \mathrm{~mm}$. A concentração de Diplodiniinae aumentou com 72\% de FDN na dieta em ambas as espécies animais. Os bubalinos apresentaram valores médios de $\mathrm{pH}$ e taxa de passagem do líquido ruminal mais elevados e volumes ruminais menores que os bovinos.
\end{abstract}

Palavras-chave: bovino, búfalo, fibra, protozoários no rúmen, ruminantes

\section{Effects of Diets with Different Levels of Neutral Detergent Fiber and the Porous Size of Nylon Bags Incubated in the Rumen on Ruminal Fauna in Buffaloes and Cattle}

\begin{abstract}
Four buffaloes and four cattle, rumen fistulated, were utilized in two Latin Square (4 $\mathrm{x} 4)$ to evaluate the effects of rations with increasing levels of NDF (54,60,66 and 72\% in DM) and two porous size of the nylon bags (53 and $100 \mathrm{~mm})$ on the population of ciliate protozoa in rumen content and inside the nylon bags suspended in the rumen for several times. There was no difference in the several genus and in the total of protozoa in the samples of the nylon bags between 53 and $100 \mathrm{~mm}$. The concentration of Entodinium and total of protozoa in the rumen content increased in the level of $66 \%$ of NDF with drop accentuated in $72 \%$ in the buffaloes, while in the cattle there was significant decrease with the increase of NDF in the ration. Rumen protozoa concentration of Diplodiniinae subfamily, Epidinium and Dasytricha were different for buffaloes and cattle inside the rumen incubated nylon bags with 53 mm pore size. Diplodiniinae concentration in the rumen content increased with $72 \%$ of NDF in diet in both animal species. The buffaloes presented higher $\mathrm{pH}$ average values and rate of passage and lower ruminal volumes than cattle.
\end{abstract}

Key Words: bovine, buffalo, fiber, rumen protozoa, ruminants

\section{Introdução}

Apesar de a maioria dos pecuaristas utilizar as plantas forrageiras para a alimentação dos ruminantes, há deficiência de informações na literatura sobre o metabolismo ruminal, em bubalinos comparativamente com bovinos. Nesse sentido, há necessidade de se conhecer nutricionalmente o aproveitamento dessas plantas pelos microrganismos ruminais, visando melhorar o sistema de produção dos ruminantes domésticos.

Em dietas experimentais para ruminantes, deve-se levar em conta a necessidade do animal e dos micror- ganismos ruminais para a maximização da produção microbiana, otimizando-se o desempenho dos animais (Kumar et al., 1993).

Alguns trabalhos comparativos indicaram ser o búfalo mais eficiente na utilização de fibras que os bovinos (Kumar at al., 1993; Franzolin, 1994). Todavia, há dúvidas sobre o real papel dos protozoários ciliados na utilização da fibra em detergente neutro de volumosos de baixa qualidade, em ambas as espécies (Nogueira Filho, 1995; Franzolin, 1996; Franzolin \& Dehority, 1999; Souza et al., 2000a,b).

\footnotetext{
${ }^{1}$ Parte da tese de Doutorado da primeira autora, apresentada à Faculdade de Medicina Veterinária e Zootecnia da UNESP, Campus de Botucatu, pesquisa financiada pela FAPESP

2Zootecnista.

${ }^{3}$ Professor Titular da Faculdade de Medicina Veterinária e Zootecnia da UNESP, Campus de Botucatu.

${ }^{4}$ Professor Titular da Faculdade de Zootecnia e Engenharia de Alimentos da USP, Campus de Pirassununga, $13635-900$ - Pirassununga - SP.

E.mail: rfranzol@usp.br
} 
Quantidades mínimas de fibra são necessárias para ter concentrações adequadas de microrganismos no rúmen a fim de garantir o processo da fermentação, produção de saliva, movimentos ruminais etc (Van Soest, 1994).

A maioria dos resultados experimentais tem mostrado maior número de protozoários do gênero Entodinium, representando $90 \%$ da concentração da população total em bovinos e ovinos. Entretanto, Franzolin (1996) observou proporções maiores de protozoários grandes da subfamília Diplodiniinae e do gênero Epidinium para bubalinos, que são os principais digestores de fibra, enquanto nos bovinos, prevalecem os ciliados pequenos dos gêneros Dasytrica e Entodinium. Ainda, neste trabalho, não foram observadas diferenças entre as degradabilidades da MS, FDN entre bubalinos e bovinos, supondo-se a não participação dos protozoários na digestão das amostras, devido à possibilidade de exclusão de ciliados nas amostras presentes nos sacos de náilon com poros de menor tamanho. Outras pesquisas com semelhantes resultados têm sido observadas com diferentes sistemas de alimentação (Franzolin \& Dehority, 1999).

O objetivo do presente trabalho foi avaliar e comparar os efeitos de dietas com quatro níveis da fibra em detergente neutro $(54,60,66$ e $72 \%$ na MS) sobre os protozoários ciliados no conteúdo ruminal e no interior de sacos de náilon com dois tamanhos de poros, e 53 e $100 \mathrm{~mm}$, incubados no rúmen de bubalinos e bovinos.

\section{Material e Métodos}

O presente experimento foi realizado na Faculdade de Zootecnia e Engenharia de Alimentos, localizada no Campus da Universidade de São de Paulo, em Pirassununga. Foram utilizados quatro bubalinos e quatro bovinos adultos das raças Mediterrâneo e Holandesa, com peso vivo médio de $540 \mathrm{~kg}$. Os animais foram mantidos em galpão experimental com cochos de alvenaria e bebedouros automáticos individuais.

Quatro rações isoprotéicas e isoenergéticas foram formuladas utilizando-se feno de capimcoastcross (Cynodon dactylon) e farelo de trigo como fontes de FDN; milho em grãos moídos, farelo de soja, óleo vegetal e uréia como fontes energéticas e nitrogenadas. Os ingredientes foram analisados para teores de MS, PB, FDN, extrato etéreo e cinzas nas amostras coletadas semanalmente, durante todo o período experimental, para controle dos níveis de FDN nas rações (Silva 1981). Os tratamentos consistiram de quatro rações contendo níveis crescentes de FDN $(54,60,66$ e 72\% na MS). As composições das rações (\%) e de seus nutrientes podem ser vistas na Tabela 1. Os animais receberam mistura completa de sal mineral colocada à disposição nos cochos todos os dias antes da alimentação. Tanto o volumoso (moído grosseiramente em moinho de alta potência) como o concentrado eram pesados diariamente e fornecidos em duas partes, no período de manhã $(8 \mathrm{~h})$ e à tarde (16 h), facilitando assim o consumo total da ração e seu controle diário sem sobras e obtenção de uma fauna ruminal mais constante ao longo do dia.

O delineamento experimental adotado foi de dois quadrados latinos ( $4 \times 4$ ), sendo um para bubalinos e outro para bovinos, com cada período experimental constituído de 21 dias para adaptação e sete dias para coletas das amostras. As amostras de conteúdo ruminal e dos sacos incubadas de cada período foram coletadas e preparadas para contagens de gêneros e espécies de protozoários, $\mathrm{pH}$, volume ruminal e taxa de passagem do líquido ruminal.

As amostragens do conteúdo ruminal foram realizadas sempre antes da alimentação matinal, durante todo o período de coleta. As coletas, bem como a preparação e coloração das amostras para contagem dos principais grupos dos protozoários ciliados Entodinium, Epidinium, Dasytrica e subfamília Diplodiniinae, foram realizadas conforme técnicas descritas por Franzolin (1996) e os protozoários foram identificados conforme técnica descrita por Dehority (1993).

Para avaliação dos efeitos da concentração de protozoários ciliados nos sacos de náilon de dois tamanhos de poros (53 e $100 \mathrm{~mm}$ ), foram colocados cerca de $5 \mathrm{~g}$ de amostras de feno de capimcoastcross, moídas em moinho com peneira de $4 \mathrm{~mm}$ para cada saco e tempo de incubação. Em seguida, todos os sacos foram incubados no rúmen ao mesmo tempo e retirados às $3,6,12,24,48,72$ e 96 horas. Após a incubação, as amostras do interior dos sacos de náilon eram transferidas para béquer, homogeneizadas, coletados volumes de $10 \mathrm{~mL}$ em cubetas e adicionados iguais volumes de formaldeído. Por serem sólidas (somente materiais fibrosos), foram preservadas com formaldeído 1:3 (diluição maior que para conteúdo ruminal) em tubos de ensaio de $20 \mathrm{x}$ $150 \mathrm{~mm}$. Amostras de conteúdo ruminal foram coletadas nos tempos 3, 6 e 12 horas, e preparadas da mesma forma que as do interior dos sacos de náilon. 
Tabela 1 - Composições percentual e químico-bromatológica das rações

Table 1 - Percentage and chemical composition of the diets

\begin{tabular}{|c|c|c|c|c|}
\hline $\begin{array}{l}\text { Ingrediente } \\
\text { Ingredient }\end{array}$ & & $\begin{array}{l}\text { Nívei } \\
\text { Leve }\end{array}$ & $\begin{array}{l}\text { rações } \\
\text { diets }\end{array}$ & \\
\hline $\begin{array}{l}\text { Feno de capim coastcross }(\%) \\
\text { Coastcross grass hay }(\%)\end{array}$ & 48,00 & 58,00 & 71,00 & 88,00 \\
\hline $\begin{array}{l}\text { Farelo de trigo (\%) } \\
\text { Wheat meal (\%) }\end{array}$ & 34,00 & 26,50 & 15,50 & - \\
\hline $\begin{array}{l}\text { Farelo de soja }(\%) \\
\text { Soybean meal (\%) }\end{array}$ & 2,50 & 5,00 & 8,50 & 10,00 \\
\hline $\begin{array}{l}\text { Milho grãos moídos }(\%) \\
\text { Ground corn grain }(\%)\end{array}$ & 15,50 & 10,50 & 5,00 & 2,00 \\
\hline $\begin{array}{l}\text { Óleo vegetal }(\mathrm{ml}) \\
\text { Vegetable oil }(\%)\end{array}$ & - & - & - & 150 \\
\hline $\begin{array}{l}\text { Uréia }(\mathrm{g}) \\
\text { Urea }(\%)\end{array}$ & - & - & - & 40 \\
\hline $\begin{array}{l}\text { Ingestão de matéria seca }{ }^{1}(\mathrm{~kg}) \\
\text { Dry matter intake }(\mathrm{kg})\end{array}$ & 6,84 & 7,66 & 7,28 & 7,93 \\
\hline $\begin{array}{l}\text { Proteína bruta }(\%) \\
\text { Crude protein }(\%)\end{array}$ & 12,46 & 12,30 & 12,22 & 12,07 \\
\hline $\begin{array}{l}\text { Fibra em detergente neutro }(\%) \\
\text { Neutral detergent fiber }(\%)\end{array}$ & 54,07 & 59,96 & 66,44 & 72,47 \\
\hline $\begin{array}{l}\text { Extrato etéreo }(\%) \\
\text { Ether extract }(\%)\end{array}$ & 2,58 & 2,16 & 1,66 & 3,01 \\
\hline $\begin{array}{l}\text { Nutrientes digestíveis totais }(\%)^{1} \\
\text { Total digestible nutrients (\%) }\end{array}$ & 68,93 & 67,60 & 66,21 & 66,61 \\
\hline $\begin{array}{l}\operatorname{Cinzas}(\%) \\
\operatorname{Ash}(\%)\end{array}$ & 4,80 & 5,10 & 5,43 & 5,56 \\
\hline $\begin{array}{l}\text { Proteína não-degradável no rúmen }(\%)^{2} \\
\text { Rumen undegradable protein (\%) }\end{array}$ & 32,70 & 31,83 & 30,86 & 27,26 \\
\hline
\end{tabular}

A leitura de $\mathrm{pH}$ foi feita imediatamente após a retirada das amostras de conteúdo ruminal, antes da alimentação, 3, 6 e 12 horas após com medidor eletrônico digital.

A taxa de passagem do líquido ruminal foi estimada utilizando-se o polietilenoglicol (PEG 4000) como marcador e introduzindo-se 120 e 100 gramas no rúmen de cada búfalo e bovino, respectivamente, e em cada período. As amostras de líquido ruminal foram coletadas às $0,1,12$ e 24 horas após a introdução do marcador, para dosagem de sua concentração pelo método colorimétrico, seguindo a técnica descrita por Hyden (1956).

Os dados obtidos foram analisados estatisticamente através do módulo GLM do programa de computador Statistical Analysis System (SAS, 1989) adotando-se nível de significância de 5\% para contrastes entre as médias e a análise de variância entre as espécies e entre sacos de náilon.

\section{Resultados e Discussão}

As concentrações médias dos diferentes grupos de ciliados no conteúdo ruminal de bubalinos e bovinos alimentados com os quatro níveis de FDN nas rações encontram-se na Tabela 2 . Os bubalinos e bovinos apresentaram diferentes concentrações da fauna ruminal entre os tratamentos. Em bubalinos, as concentrações de Entodinium e do total de protozoários no conteúdo ruminal aumentaram até o nível de $66 \%$ de FDN, ocorrendo grande redução com $72 \%$ de FDN. Porém, nos bovinos houve diminuições com a elevação dos níveis de FDN nas rações $(\mathrm{P}<0,05)$. As dietas com níveis crescentes de FDN afetaram mais a população de ciliados no conteúdo ruminal dos bovinos que dos bubalinos, apesar de haver redução do número total e de quase todos os gêneros de protozoários ciliados com nível alto de FDN em ambas espécies. Isto é observado 
na revisão de Jouany (1989), o qual cita que, em dietas à base de volumosos comparadas com concentrados, o número de protozoários é geralmente menor e que os protozoários maiores da família Diplodiniinae e de Epidinium são os mais freqüentemente encontrados.

A composição de protozoários da subfamília Diplodiniinae elevou-se $(\mathrm{P}<0,05)$ com níveis crescentes de FDN nos bubalinos e nos bovinos, representando 42,3 e 17,9\% do total de protozoários ciliados, respectivamente, em $72 \%$ de FDN na dieta (Tabela 2 ). Dados semelhantes com ruminantes foram citados por Dehority (1991), que classificou esses protozoários como celulolíticos, e, segundo Marinho (1998), os Diplodiniinae aparecem normalmente associados com rações de composição mista, mas onde o componente da fibra é importante. Houve maior proporção do gênero Entodinium nos três primeiros tratamentos $(\mathrm{P}<0,05)$ em bubalinos e bovinos. Estes achados concordam com a maioria dos resultados experimentais existentes na literatura quanto à composição de Entodinium em bovinos (acima de $80 \%$ ), exceto no tratamento com $72 \%$ FDN $(59,7 \%)$ e confirma os dados obtidos por Franzolin (1996) e Franzolin et al. (1998) que observaram proporções maiores de protozoários da subfamília Diplodiniinae e do gênero Epidinium para bubalinos alimentados com alto nível de volumoso na ração. Porém, os bubalinos apresentaram alta proporção de Entodinium nos níveis 54, 60 e $66 \%$ de FDN (média 77,0\%).

Não houve diferenças $(\mathrm{P}>0,05)$ para todos os grupos de ciliados estudados entre os sacos de náilon com dois tamanhos de poros (53 e $100 \mathrm{~mm}$ ) e nem interação entre tratamento $\mathrm{x}$ espécie animal x tamanho de poros. Assim, foram usados somente os resultados obtidos com $53 \mathrm{~mm}$ devido ser o tamanho de poro mais freqüentemente utilizado na técnica de degradabilidade in situ (Huntington \& Givens, 1995). Lindberg et al. (1984) observaram que com aumentos dos tamanhos de poros de 10 e 20 para $36 \mathrm{~mm}$ diminuíram as concentrações de protozoários dentro dos sacos. De acordo com Nozière \& MichaletDoreau (1996), o tempo gasto pelas partículas no rúmen, a falta de mastigação e o confinamento do alimento nos sacos podem afetar a atividade fibrolítica entre os microrganismos presentes no conteúdo ruminal e nos sacos. E também as possibilidades de troca entre as partículas dos alimentos e o meio ruminal são limitadas nos sacos pela área de superfície dos poros no material dos sacos (Lindberg et al., 1984). Neste

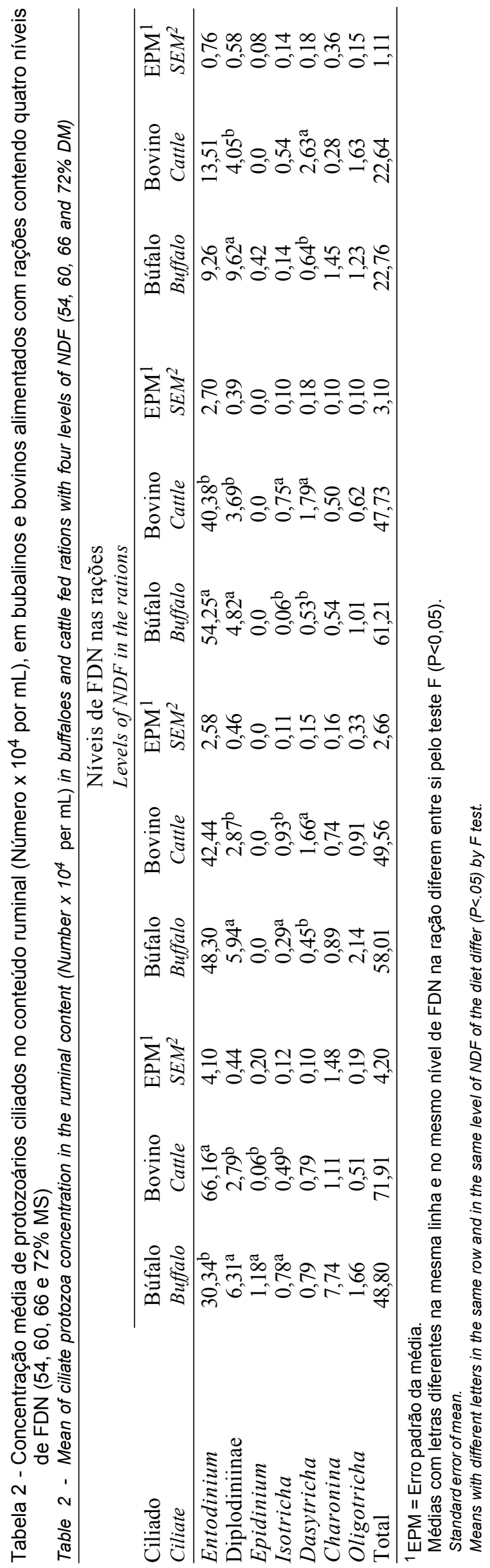


trabalho a relação do peso da amostra por área de superfície do saco foi de $44 \mathrm{mg}$ de amostra $/ \mathrm{cm}^{2}$.

$\mathrm{Na}$ Tabela 3 encontram-se as concentrações médias dos ciliados dentro dos sacos de náilon com porosidade de $53 \mathrm{~mm}$ em bubalinos e bovinos alimentados com os quatro níveis de FDN nas rações. As condições do alimento nos sacos de náilon diferem das condições naturais do alimento dentro do rúmen. Observaram-se menores concentrações totais e de todos os gêneros de protozoários nos sacos de náilon em comparação ao conteúdo ruminal.

Não foram observadas diferenças $(\mathrm{P}>0,05)$ para a maioria dos diversos gêneros de protozoários e do total de protozoários nos sacos de náilon com poros de $53 \mathrm{~mm}$ entre tratamentos em bubalinos e bovinos, com exceções do Epidinium, que apareceu somente no conteúdo ruminal de bovinos em $54 \%$ de FDN; da subfamília Diplodiniinae, com $72 \%$ de FDN, que foi maior nos sacos incubados em bubalinos, e de Dasytricha, que foi maior em bovinos (Tabela 3 ).

No geral, os bubalinos apresentaram maior concentração total e dos grupos de protozoários no conteúdo ruminal que bovinos $(\mathrm{P}<0,05)$ exceto para os Entodinium onde não houve diferença entre ambas espécies animais conforme observado na Tabela 4 . Os bubalinos também tiveram maiores concentrações de Diplodiniinae, Isotricha, Dasytrica, Charonina e Oligotricha no conteúdo ruminal e dentro dos sacos com poros de $53 \mathrm{~mm}$, com exceção dos Charonina e Dasytricha que foram maiores para bovinos no interior dos sacos $(\mathrm{P}<0,05)$. As duas espécies animais mantiveram composições da fauna similares no conteúdo ruminal e dentro dos sacos de náilon, indicando uma boa troca das espécies de ciliados entre os dois ambientes. Meyer \& Mackie (1986), citados por Huntington \& Givens (1995) e Varvikko \& Lindberg (1985) verificaram em sacos com poros de 30 e $40 \mathrm{~mm}$, colonizações mais diversificadas e adequadas de protozoários e bactérias comparadas com poros menores de 10 e $20 \mathrm{~mm}$.

As concentrações de Entodinium, da subfamília Diplodiniinae e de total de protozoários no interior dos sacos com porosidade de $53 \mathrm{~mm}$ nos diferentes tempos em bubalinos e bovinos podem ser observada na Figura 1. Os protozoários da subfamília Diplodiniinae mostraram um comportamento semelhante em ambas espécies apresentando somente maior número nos bubalinos enquanto que os entodíneos e total de protozoários nos bovinos apresentaram oscilações maiores, atingindo um pico às 48

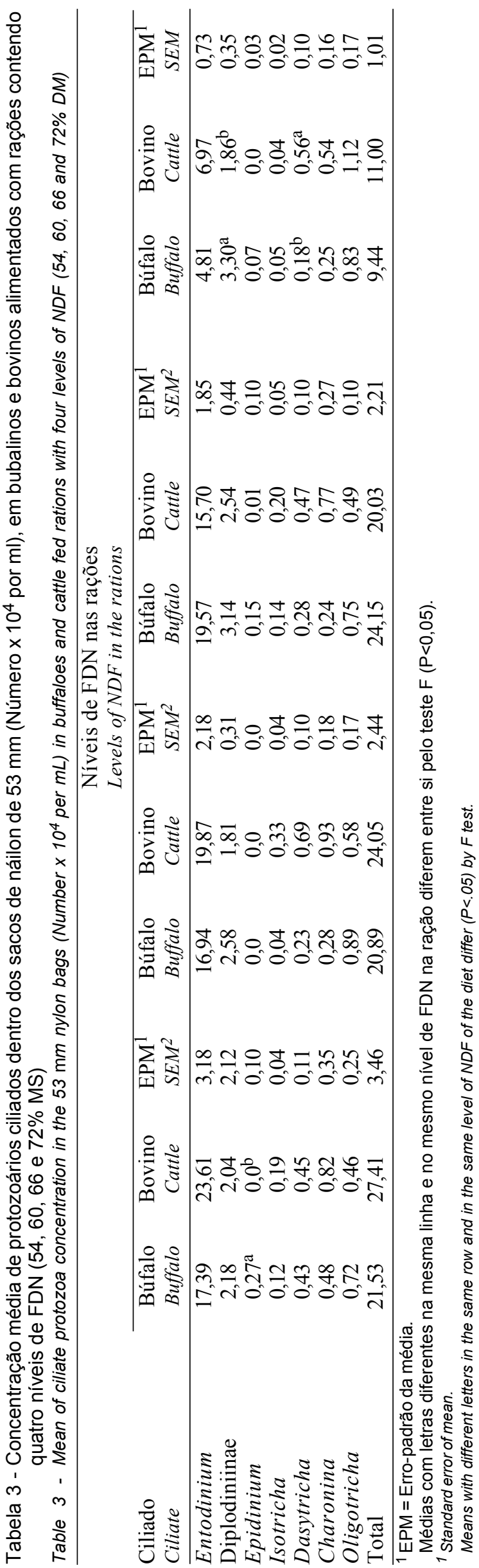


Tabela 4 - Concentração média geral de protozoário ciliados no conteúdo ruminal e em sacos de náilon com porosidade 53 $\mathrm{mm}$ (Número $\times 10^{4}$ por $\mathrm{ml}$ ), em bubalinos e bovinos alimentados com rações contendo quatro níveis de FDN

Table 4 - Ciliate protozoa general mean concentration in the ruminal content and inside nylon bags with $53 \mathrm{~mm}$ pore size, in buffaloes and cattle fed rations with four levels of NDF

\begin{tabular}{|c|c|c|c|c|c|c|}
\hline \multirow{3}{*}{$\begin{array}{l}\text { Protozoário } \\
\text { Protozoa }\end{array}$} & \multicolumn{3}{|c|}{$\begin{array}{l}\text { Conteúdo ruminal } \\
\text { Content ruminal }\end{array}$} & \multicolumn{3}{|c|}{$\begin{array}{l}\text { Sacos com poros de } 53 \mathrm{~mm} \\
\text { Bags with } 53 \mathrm{~mm} \text { pore }\end{array}$} \\
\hline & Búfalo & Bovino & EPM $^{1}$ & Búfalo & Bovino & $\mathrm{EPM}^{1}$ \\
\hline & Buffalo & Cattle & $S E M^{2}$ & Buffalo & Cattle & $S E M^{2}$ \\
\hline$\overline{\text { Entodinium }}$ & 37,22 & 35,91 & 1,85 & 14,68 & 16,53 & 1,10 \\
\hline Diplodiniinae & $6,12^{\mathrm{a}}$ & $3,35^{\mathrm{b}}$ & 0,25 & $2,80^{\mathrm{a}}$ & $2,04^{\mathrm{b}}$ & 0,19 \\
\hline Epidinium & $0,40^{\mathrm{a}}$ & $0,02^{b}$ & 0,10 & $0,12^{\mathrm{a}}$ & $0,01^{\mathrm{b}}$ & 0,03 \\
\hline Isotricha & $0,68^{\mathrm{a}}$ & $0,32^{b}$ & 0,10 & 0,09 & 0,19 & 0,02 \\
\hline Dasytricha & $1,72^{\mathrm{a}}$ & $0,60^{\mathrm{b}}$ & 0,10 & $0,28^{\mathrm{b}}$ & 0,54 & 0,05 \\
\hline Charonina & $2,62^{\mathrm{a}}$ & $0,69^{\mathrm{b}}$ & 0,50 & $0,31^{\mathrm{b}}$ & $0,77^{\mathrm{a}}$ & 0,13 \\
\hline Oligotricha & $1,51^{\mathrm{a}}$ & $0,92^{\mathrm{b}}$ & 0,11 & 0,80 & 0,66 & 0,10 \\
\hline Total & $50,27^{\mathrm{a}}$ & $41,21^{b}$ & 1,72 & 19,07 & 20,74 & 1,23 \\
\hline
\end{tabular}

${ }^{1}$ EPM $=$ Erro-padrão da média.

Médias com letras diferentes na mesma linha e no conteúdo ruminal ou nos sacos com $53 \mathrm{~mm}$ diferem entre si pelo teste $F(P<0,05)$.

${ }^{1}$ SEM $=$ Standard error of mean.

Means with different letters in the same row and in the ruminal content or in the bags pore size with $53 \mathrm{~mm}$ differ at $P<.05$.

horas, ocorrendo o contrário nos bubalinos. Porém, conforme observado na Figura 2, ambas espécies apresentaram resultados semelhantes para o conteúdo ruminal com redução na concentração de Entodinium e de total até 6 horas, havendo após, tendência de aumento em ambas espécies, concordando com o gráfico obtido por Jouany \& Sevaud (1979) e também com a observação de Dennis et al. (1983) de que o tempo após a alimentação foi um importante fator que afetou o número de entodiniomorfos, com elevação antes e às 6 horas após a alimentação. Vários fatores podem influenciar

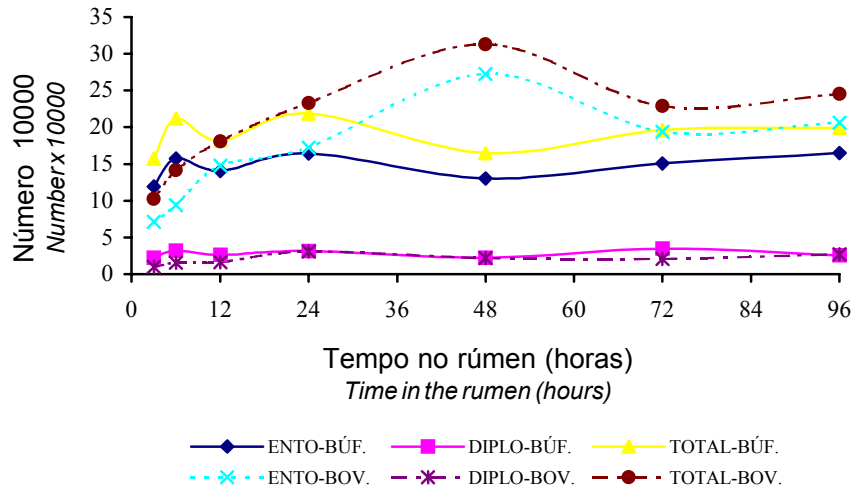

Figura 1 - Concentração de Entodinium, Diplodiniinae e total de ciliados no interior de sacos com poros de $53 \mathrm{~mm}$ incubados no rúmen de búfalos e bovinos.

Figure 1 - Concentration of Entodinium, Diplodiniinae and total of ciliates inside the nylon bags with $53 \mathrm{~mm}$ incubated in the rumen of buffalo and cattle. diferentemente os gêneros de protozoários ciliados, decorrente do tempo após a ingestão alimentar, entre eles, a ingestão alimentar, o tempo de divisão celular, a taxa de diluição do retículo-rúmen e a competição entre espécies (Jouany \& Sevaud, 1979).

Os níveis crescentes de FDN (54, 60, 66 e 72\%) influenciaram $(\mathrm{P}<0,05)$ o volume do rúmen e a taxa de passagem do líquido ruminal em bubalinos e bovinos, respectivamente, ocorrendo tendência de redução da taxa de passagem em bubalinos e aumento do volume ruminal em bovinos (Tabela 5). O nível mais alto de FDN promoveu aumento $(\mathrm{P}<0,05)$ do volume

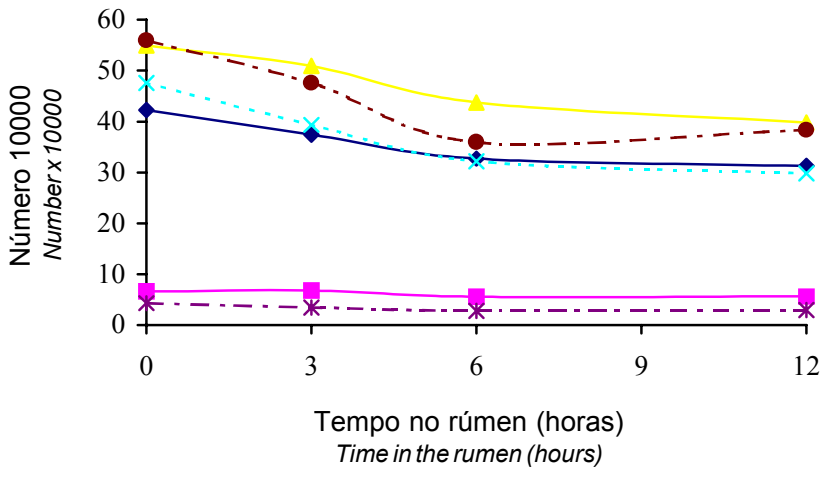

$\longrightarrow$ ENTO-BÚF. $\longrightarrow$ DIPLO-BÚF. $\longrightarrow$ TOTAL-BÚF.
$\cdots--$ ENTO-BOV. $-*-$ DIPLO-BOV. - - TOTAL-BOV.

Figura 2 - Concentração de Entodinium, Diplodiniinae e total de protozoários no conteúdo ruminal em búfalos e bovinos.

Figure 2 - Concentration of Entodinium, Diplodiniinae and total of protozoa in the rumen content of buffalo and cattle. 
do rúmen nos bubalinos, em relação ao nível mais baixo. Estes dados são semelhantes aos de Punia \& Sharma (1987) e contrários às observações de Adams \& Kartchner (1984) onde, em bovinos, o volume ruminal diminuiu linearmente com ingestões crescentes de volumosos. Em relação à taxa de passagem, esses resultados são contrários aos encontrados por Poore et al. (1990), que observaram em bovinos alimentados com nível mais elevado de fibra maior taxa de passagem do conteúdo ruminal.

Os bubalinos apresentaram curvas de $\mathrm{pH}$ com valores médios mais altos que os bovinos, como se pode observar na Figura 3. Franzolin \& Dehority (1999) não verificaram diferenças no $\mathrm{pH}$ ruminal entre essas mesmas espécies alimentadas somente com volumosos e também Nogueira Filho (1995) não detectou diferença entre bovinos e bubalinos em amostragens de líquido ruminal retiradas a cada 2 horas por um período de 24 horas.

No presente trabalho, as diferenças ocorridas entre bubalinos e bovinos, como a maior composição dos protozoários celulolíticos no conteúdo ruminal

Tabela 5 - Volume ruminal em litros (VR) e taxa de passagem do líquido ruminal em \%/h (TP) em bubalinos e bovinos alimentados com quatro níveis de FDN na ração

Table 5 - Ruminal volume in liters (RV) and ruminal fluid passage rate in \%/h (RP) in buffaloes and cattle fed diet with four NDF levels

$\begin{array}{llll}\text { Níveis de FDN nas rações } & \text { Média } & \mathrm{CV}^{1} & \mathrm{EPM}^{2}\end{array}$

Levels of $N D F$ in the rations

Mean SEM

\begin{tabular}{|c|c|c|c|c|c|c|c|}
\hline $\begin{array}{l}\text { Búf } \\
\text { Buff }\end{array}$ & & & & & & & \\
\hline $\begin{array}{l}\mathrm{VR} \\
R V\end{array}$ & $62,05^{\mathrm{b}}$ & $79,30^{\text {ba }}$ & $73,53^{\mathrm{ba}}$ & $90,30^{\mathrm{a}}$ & 76,29 & 17,91 & 3,41 \\
\hline $\begin{array}{l}\mathrm{TP} \\
R P\end{array}$ & 8,97 & 8,94 & 8,71 & 7,51 & 8,53 & 16,51 & 0,35 \\
\hline $\begin{array}{l}\text { Bov } \\
\text { Catt }\end{array}$ & & & & & & & \\
\hline $\begin{array}{l}\mathrm{VR} \\
R V\end{array}$ & 79,84 & 68,11 & 93,43 & 95,90 & 84,32 & 20,41 & 4,3 \\
\hline $\begin{array}{l}\mathrm{TP} \\
R P\end{array}$ & $6,81^{b a}$ & $8,24^{\mathrm{a}}$ & $5,78^{b}$ & $6,62^{\mathrm{ba}}$ & 6,86 & 22,44 & 0,39 \\
\hline
\end{tabular}

${ }^{1}$ Coeficiente de variação (\%); ${ }^{2} \mathrm{EPM}=$ erro-padrão da média.

Médias com letras diferentes na mesma linha diferem pelo teste LSD $(P<0,05)$.

${ }^{1}$ Coefficient of variation (\%), ${ }^{2}$ SEM $=$ standard error of mean.

Means followed by different letters in the same row differ $(P<.05)$ by $D S L$ test.

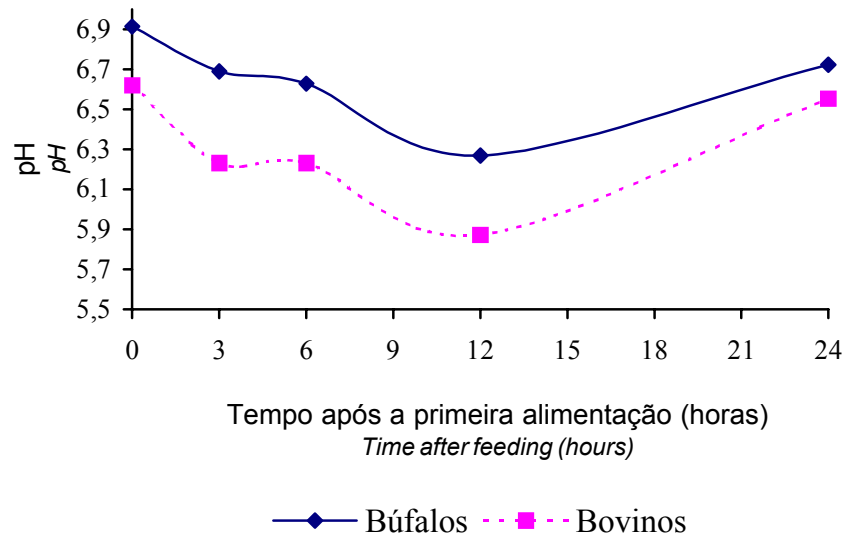

Figura 3 - Valores médios de $\mathrm{pH}$ do conteúdo ruminal de búfalos e bovinos sob dietas com diferentes níveis de FDN.

Figure 3 - Average values of $\mathrm{pH}$ of ruminal content of buffalo and cattle fed diets with different NDF levels.
(Diplodiniinae) no nível de $72 \%$ de FDN na ração; o aumento do total dos protozoários no conteúdo ruminal até o nível de $66 \%$ de FDN; o pH e a taxa de passagem mais elevados e o volume ruminal menor, indicam em parte, uma melhor adaptação dos bubalinos aos alimentos com alto teor de fibra.

\section{Conclusões}

Os níveis crescentes de FDN produzem efeitos diferentes na fauna ruminal de bubalinos e de bovinos, sendo que, nos bubalinos, a concentração de Entodinium e o número total de protozoários aumentam até o nível de $66 \%$ de FDN, promovendo queda acentuada com $72 \%$, e nos bovinos, ocorre redução desses mesmos protozoários com o aumento de FDN na ração. 
A concentração de protozoários da subfamília Diplodiniinae no conteúdo ruminal eleva-se com o nível mais alto de FDN (72\%) em ambas espécies animais.

O tamanho de poros de 53 ou $100 \mathrm{~mm}$ dos tecidos dos sacos de náilon não influencia a concentração e a composição da fauna ruminal existente nas amostras de feno de capim-coastcross incubadas no rúmen em bubalinos e em bovinos.

Os bubalinos e os bovinos diferem no comportamento da fauna no interior dos sacos de náilon ao longo do tempo de incubação no rúmen, mantendo nos bubalinos concentrações de Entodinium e total de protozoários próximas (constantes) ao longo dos tempos incubados, enquanto que nos bovinos ocorre aumento desses ciliados atingindo um pico em 48 horas de incubação, declinando em seguida.

Os bubalinos apresentam valores médios de $\mathrm{pH}$ e taxa de passagem do líquido ruminal mais elevados, porém apresentaram volumes ruminais menores que os bovinos.

\section{Literatura Citada}

ADAMS, D.C.; KARTCHNER, R.J. Effect of level of forage intake on rumen ammonia, $\mathrm{pH}$, liquid volume and liquid dilution rate in beef cattle. Journal of Animal Science, v.58, n.3, p.708713,1984

AGRICULTURAL RESEARCH COUNCIL - ARC. The nutrient requirements of ruminants livestock. Wallingford: $\mathrm{CAB}$ International, 1980. 351p.

DEHORITY, B.A. Rumen microbiology. Wooster: OARDC/ OSU, 1991. 276p.

DEHORITY, B.A. Laboratory manual for classification and morphology of rumen ciliate protozoa. Florida: CRC Press, 1993. 96p.

DENNIS, S.M.; ARAMBEL, M.J.; BARTLEY, E.E. et al. Effect of energy concentration an source of nitrogen on numbers and types of rumen protozoa. Journal of Dairy Science, v.66, n.6, p.284-1354, 1983.

FRANZOLIN, R. Feed efficiency: a comparison between cattle and buffalo. Buffalo Journal, S2, p.39-50, 1994.

FRANZOLIN, R. Comparação da fauna ruminal e da degradabilidade da dieta entre bubalinos e bovinos zebuínos alimentados à base de cana-de-açúcar. Pirassununga: Universidade Federal de São Paulo, 1996.78p. Tese(Livre-Docência) - Universidade de São Paulo, 1996, 78p.

FRANZOLIN, R.; FRANZOLIN, M.H.T.; SILVA, J.R. Avaliação da população de protozoários ciliados no rúmen, retículo e omaso e do trato digestivo em bubalinos alimentados em três níveis de energia. Revista de la Facultad de Agronomia, v.15, p.58-63, 1998

FRANZOLIN, R.; DEHORITY, B.A. Comparison of protozoal populations and digestion rates between water buffalo and cattle fed an all forage diet. Journal of Applied Animal Research, v.16, p.33-46, 1999.

HUNTINGTON, J.A.; GIVENS, D.I. The in situ technique for studding the rumen degradation of feeds: a review of procedure. Nutrition Abstracts Review (Series B), CAB International, v.65, n.2, p.63-93, 1995.
HYDEN, S.A. A turbidimetric method for the determination of higher polyethylene glycol in biological material. KGL Lantbruks-hogskol Annales Uppsala, v.22, p.139-145, 1956.

JOUANY, J.P.; SEVAUD, J. Role of rumen protozoa in the digestion of food cellulosic materials. Annales de Recherches Veterinaires, v.10, p.261-263, 1979.

JOUANY, J.P. Effects of diet on populations of rumen protozoa in relation to fibre digestion. In: NOLAN, J.V.; LENG, R.A.; DEMEYER, D.I. (Eds.) The roles of protozoa and fungi in ruminant digestion. Armidale: Penambul Books, 1989. p.59-74.

KUMAR, R.; SANGWAN, D.C.; BHATIA, S.K. et al. Intraruminal metabolism and nutrient digestion in cattle and bovine fed low grade roughages supplemented with protein sources. Indian of Journal Animal Science, v.63, n.5, p.561-565, 1993.

LINDBERG, J.E.; KASPERSSON, A.; CISZVK, P. Studies on pH number of protozoa and microbial ATP concentrations in rumen - incubated nylon bags with different pore size. Journal of Agriculture Science, v.102, p.501-504, 1984.

MARINHO, A.A. Protozoários ciliados do retículo-rumen Revisão. Revista Portuguesa de Ciência Veterinária, v.43, p.173-185, 1998.

NOGUEIRA FILHO, J.C.M. Estudo da degradabilidade in situ e de protozoários ciliados com zebuínos da raça nelore (Bos taurus indicus) e de bubalinos (Bubalus bubalis) submetidos a dietas com volumosos e concentrados. Pirassununga: Universidade de São Paulo, 1995. 144p. Tese (Livre-docência) Universidade de São Paulo, 1995.

NOZIĖRE, P.; MICHALET-DOREAU, B. Validation of in sacco method: influence of sampling site, nylon bag or rumen contents, on fibrolytic activity of solid-associated microorganisms Animal Feed Science and Technology, v.57, p.203-210, 1996.

POORE, M.; MOORE, J.A.; SWINGLE, R.S. Differential passage rates and digestion of neutral detergent fiber from grain and forages in 30,60 and 90\% concentrate diets ffed to steers. Journal of Animal Science, v.62, p.2965-2973, 1990.

PUNIA, B.S.; SHARMA, D.D. Rumen fluid volume and outflow to the omasum in buffaloes and cattle fed lucerne hay and three energy supplements. Indian Journal of Animal Science, v.57, n.11, p.1238-1241, 1987.

SAS INSTITUTE. Statistical Analysis System, Cary: 1989.

SILVA, D.J. Análise de alimentos (métodos químicos e biológicos). Viçosa, MG: Universidade Federal de Viçosa, 1981. 166p.

SOUZA, N.H.; FRANZOLIN, R.; RODRIGUES, P.H.M. et al. Efeitos de níveis crescentes de fibra em detergente neutro na dieta sobre a fermentação ruminal em bubalinos e bovinos. Revista Brasileira de Zootecnia, v.29, n.5, p.1553-1564, 2000a.

SOUZA, N.H.; FRANZOLIN, R.; RODRIGUES, P.H.M. et al. Efeitos de níveis crescentes de fibra em detergente neutro na dieta sobre a digestão ruminal em bubalinos e bovinos. Revista Brasileira de Zootecnia, v.29, n.5, p.1565-1577, 2000b.

Van SOEST, P.J. Nutritional ecology of the ruminant. 2.ed. Ithaca: Cornell University Press, 1994. 476p.

VARVIKKO, T.; LINDBERG, J.E. Estimation on microbial nitrogen in nylon-bag residues by $15 \mathrm{~N}$ dilution. British Journal Nutrition, v.54, p.473-481, 1985. 